\title{
Self-Esteem Maintenance Processes: Why Low Self-Esteem May Be Resistant to Change
}

\author{
Robert A. Josephs \\ The University of Texas at Austin \\ Jennifer K. Bosson \\ The University of Oklahoma \\ Christopher G. Jacobs \\ Fulbright E Jaworski, LLP
}

If most people desire to maximize feelings of self-worth, how do we explain the persistence of low self-esteem? Results from four studies suggest that people with low self-esteem may be less likely to accept positive feedback from themselves than from an outside source but equally likely to accept negative feedback from the self and an outsider. When the self was the source of positive feedback, people high, but not low, in self-esteem incorporated the feedback into their self-views; in contrast, when positive feedback came from a knowledgeable external source, both high and low self-esteem people accepted it. Finally, when self-generated feedback was negative, participants low in self-esteem accepted it. The authors discuss how these findings shed light on the maintenance of low self-esteem.

Keywords: self-esteem; positive feedback; negative feedback; self-worth; source credibility

$\mathbf{O}$ nce established, self-esteem tends to remain stable across time (Baumeister, 1993). Research has shed light on many of the mechanisms that promote maintenance of high self-esteem (e.g., Steele, 1988; Taylor \& Brown, 1988; Tesser, 1988) but much remains to be learned about the mechanisms that promote stability of low selfesteem.

Our goal in this article is to explore the idea that low self-esteem may maintain itself, in part, by making the individual immune to the beneficial effects of certain forms of esteem-enhancing feedback. Specifically, we propose that people with low self-esteem are less able or willing to accept positive feedback from themselves than from an outsider. Although others have speculated about the possibility that low self-esteem persons do not accept positive feedback from themselves (e.g., Blaine \& Crocker, 1993), this phenomenon has not yet been tested empirically. We therefore present a series of studies in which we explore the implications for self-esteem maintenance represented by self-generated feedback (feedback issued by the individual) versus externally generated feedback (feedback from an outsider). We believe that this investigation allows insight into what Baumeister (1993) has termed "the puzzle of low selfregard" (p. 201).

\section{LOW SELF-ESTEEM AND POSITIVE} SELF-GENERATED FEEDBACK

Several theoretical perspectives can be invoked to explain why a person with low self-esteem might fail to acknowledge and/or accept positive self-generated feedback. For example, Baumeister, Tice, and Hutton's (1989) self-presentational model is based on the assumption that low self-esteem persons adopt a cautious and self-protective interpersonal style so as to avoid humiliation and/or loss of face. By assiduously avoiding a posture that might cause others to see them as proud or boastful, people with low self-esteem forestall the shame

Authors' Note: We are grateful to Agatha Maciejewski and Courtney Pearson for their assistance with data collection. Correspondence concerning this article should be directed to Robert A. Josephs, Department of Psychology, University of Texas, 1 University Station A8000, Austin, TX 78712-0187; e-mail: josephs@psy.utexas.edu.

PSPB, Vol. 29 No. 7, July 2003 920-933

DOI: $10.1177 / 0146167203253124$

(C) 2003 by the Society for Personality and Social Psychology, Inc. 
that would result if their performance or abilities fell short of their claims. However, their self-protective orientation may render low self-esteem people relatively immune to their own internal feelings of success because were they to trust their positive self-generated feedback, they might appear boastful. On the other hand, Baumeister et al.'s model allows for the possibility that low-self-esteem people will accept positive feedback from an outsider because claiming success based on externally generated feedback does not appear as boastful-and is therefore not as risky-as claiming success based on self-assessment of one's performance.

From another perspective, people with low selfesteem may be relatively inattentive to self-generated feedback in general because they are preoccupied instead with others' evaluations of them. According to Leary's (Leary \& Downs, 1995; Leary, Tambor, Terdal, \& Downs, 1995) sociometer theory, feelings of low selfesteem arise when the individual perceives that she is about to be rejected or excluded by others. Because inclusion in social groups is important for survival (e.g., Bowlby, 1969), people who chronically fear exclusion, that is, low self-esteem persons, should be particularly sensitive to other people's evaluations of them. Although hypervigilant to feedback that connotes acceptance or rejection by others, people with low self-esteem may be less attuned to their own feelings of success or failure because these feelings are not directly tied to their inclusionary status.

A third possibility is that people with low self-esteem simply do not see themselves as credible sources of positive feedback and are therefore reluctant to accept such feedback. Research on persuasion has established that people are less influenced by information from a lowas compared to a high—credibility source (e.g., Petty \& Cacioppo, 1986). Thus, when the source of self-relevant information (feedback) is viewed as inaccurate or untrustworthy, people may refuse to accept the feedback. On the other hand, when the source of feedback is regarded as knowledgeable and trustworthy, people may accept the feedback as veridical and adjust their selfviews accordingly. Given that low self-esteem persons have relatively negative and unconfident self-views (e.g., Campbell, 1990), it follows that they may perceive themselves as noncredible sources of positive feedback (cf. Brockner, 1988, p. 29). In contrast, low self-esteem persons may view an "expert," such as a knowledgeable experimenter, as a highly credible source of positive feedback. This idea is consistent with Blaine and Crocker's (1993) proposal that "people who are low in self-esteem have trouble believing their intrapsychic attempts at self-enhancement. Hence, they rely on eliciting positive reactions from others to enhance the self" (p. 80; see also Baumgardner, Kaufman, \& Levy, 1989).
Regardless of why people low in self-esteem hesitate to accept positive self-generated feedback, we propose here that their tendency to ignore subjective, self-generated feelings of success may play an important role in the maintenance of their low self-esteem. In the absence of feedback from an external agent, when people with low self-esteem perform well on a task, they may remain unaffected by this positive self-generated feedback. Conversely, people with high self-esteem should accept positive feedback from both a credible outsider and the self. Unlike their low self-esteem counterparts, people with high self-esteem focus attention on their positive qualities (Baumeister et al., 1989), do not characteristically fear rejection from others (Leary et al., 1995), and hold highly favorable self-views (e.g., Brown, 1991); thus, high self-esteem persons should embrace positive feedback and incorporate it into their self-views, regardless of its source.

\section{OVERVIEW OF STUDIES}

We conducted four studies to test the assumption that people with low self-esteem are reluctant to accept positive feedback from the self. In Study 1, we looked to see whether people with low versus high self-esteem differ in their willingness to accept positive self- and experimentergenerated feedback about their performance on a novel, competence-relevant task (a series of anagrams). We used the same anagram series in Study 2 to examine whether the state self-esteem of people low versus high in trait self-esteem was differentially affected by positive self- and experimenter-generated feedback. In Study 3, we explored the possibility that people low in self-esteem would accept self-generated feedback on an anagram task if it matched the general valence of their self-views (i.e., if it was negative). Finally, we utilized a self-report methodology in Study 4 to test the hypothesis that people with low versus high self-esteem differ in the extent to which they trust and accept self-generated positive feedback in both social and competence-relevant domains. Taken together, the purpose of these studies was to demonstrate the ironic fact that the very people who are often most in need of a self-esteem boost-those chronically low in self-esteem-may find it particularly difficult to assimilate positive self-generated feedback into their self-views.

\section{PILOT STUDY}

In Studies 1 through 3, we operationalized selfgenerated feedback as a noticeable change in performance across a series of anagrams. Past research suggests that anagrams may be ideal for the administration of selfgenerated feedback because participants typically have little or no prior experience with anagrams (Shrauger \& 
Sorman, 1977) and it is fairly easy to manipulate participants' subjective assessments of performance by changing the order in which a series of anagrams is administered (Josephs, Silvera, \& Giesler, 1996). To establish that our anagram manipulation produced the intended self-generated feedback effects, we conducted a pilot study. We sought to show that when anagrams are ordered from most to least difficult (or from least to most difficult), participants correctly perceive changes in the difficulty of the anagrams as well as changes in their speed at solving the anagrams. An additional purpose of the pilot study was to explore self-esteem differences in reactions to the neutral, experimenter-generated feedback that we planned to use in the ensuing studies.

We recruited 20 introductory psychology students who scored in the bottom 25th percentile and 19 who scored in the top 25th percentile $(M s=3.16$ and 5.41, respectively) on Tafarodi and Swann's (1995) Self-Liking and Self-Competence Scale (SLCS). The SLCS consists of 20 statements pertaining to people's feelings of selfworth and competence; responses were made on scales of 1 (strongly disagree) to 7 (strongly agree) and were internally consistent $(\alpha=.93)$.

Participants began by completing a booklet containing a series of 12 five-letter anagrams. We manipulated the order of the anagrams to produce three self-generated feedback conditions: descending difficulty (anagrams were ordered from most to least difficult), ascending difficulty (anagrams were ordered from least to most difficult), and constant difficulty (anagram order was randomized). Difficulty of the anagrams was operationalized as normative solution time and was established in earlier research conducted by the first author.

Following the anagram task, the experimenter took participants' anagram booklets to "look them over"; in the meantime, participants used scales anchored by 1 (strongly disagree) and 9 (strongly agree) to rate their agreement with six statements about the anagram series and their own solution times. Two of these items ("The anagrams got easier as I proceeded through the series" and "I found that I was able to solve the anagrams more and more quickly as I went along") were correlated at $r=.70$, $p<.001$, so we combined them into a single measure of perceived descending difficulty of the anagrams. Two more items ("The anagrams got more difficult as I proceeded through the series" and "I found that I became slower and slower at solving the anagrams as I went along") were correlated at $r=.77, p<.001$, so we combined them into a single measure of perceived ascending difficulty of the anagrams. The remaining two items ("The difficulty level of the anagrams stayed about the same as I proceeded through the series" and "I found that my speed at solving the anagrams did not change much as I went along") were correlated at $r=.62, p<.001$, so we combined them into a single measure of perceived constant difficulty of the anagrams.

After participants made these ratings, the experimenter returned and administered a dose of neutral performance feedback; specifically, she told the participant that "you did about how I expected" on the anagrams. She then left participants with a final questionnaire on which they rated, using scales ranging from 1 (not at all) to 9 (very), how positive, negative, and neutral the experimenter-generated feedback was (in addition to several filler items).

We submitted participants' perceptions of anagram difficulty to a 2-between (self-esteem: low vs. high) $\times 3$ between (anagram difficulty order: descending vs. ascending vs. constant) $\times 3$-within (perceived change in difficulty: descending vs. ascending vs. constant) ANOVA (means and standard deviations appear in Table 1). A significant Anagram-Difficulty-Order $\times$ PerceivedChange interaction emerged, $F(4,66)=30.29, p<.001$. In the descending difficulty condition, participants rated the anagrams higher in descending difficulty than in either ascending or constant difficulty; in the ascending difficulty condition, participants rated the anagrams higher in ascending difficulty than in either descending or constant difficulty, and in the constant difficulty condition, participants rated the anagrams higher in constant difficulty than in either descending or ascending difficulty. Across all conditions, participants perceived more descending difficulty in the anagram series than either ascending or constant difficulty, $F(2,66)=4.25$, $p$ $<.05$. Important for our purposes, however, there was no main effect of self-esteem on perceived change; selfesteem did not interact with perceived change, and the three-way interaction was not significant, all $F \mathrm{~s}<1$. $^{1}$

Next, a 2-between (self-esteem: low vs. high) $\times$ 3between (anagram difficulty order: descending vs. ascending vs. constant) $\times 3$-within (perceptions of feedback: positive vs. negative vs. neutral) ANOVA revealed the expected main effect of perceptions of the experimenter-generated feedback (see Table 1). Overall, participants rated the feedback as more neutral than either positive or negative, $F(2,62)=34.06, p<.001 .^{2}$ Perceptions of the feedback did not interact with either anagram difficulty order, $F(4,62)<1$, or self-esteem, $F(2,62)$ $=1.25, p=.29$, and the three-way interaction was not significant, $F(4,62)=1.17, p=.33 .^{3}$

In summary, both low and high self-esteem participants perceived changes in their solution times, that is, their performance, across the series of anagrams. The anagrams therefore seemed like a reasonable method by which we could administer performance feedback without input from an outside agent. Moreover, there were no self-esteem differences in perceptions of the neutral, 
TABLE 1: Means and Standard Deviations for Perceived Improvement and Perceptions of the Neutral Feedback (Pilot Study)

\begin{tabular}{|c|c|c|c|c|c|c|}
\hline \multirow[b]{3}{*}{ Self-Esteem/Dependent Measure } & \multicolumn{6}{|c|}{ Anagram Difficulty Order Condition } \\
\hline & \multicolumn{2}{|c|}{ Descending } & \multicolumn{2}{|c|}{ Constant } & \multicolumn{2}{|c|}{ Ascending } \\
\hline & M & SD & M & SD & M & SD \\
\hline \multicolumn{7}{|l|}{ Low self-esteem/perceptions of } \\
\hline Descending difficulty & 7.56 & 0.86 & 4.57 & 1.30 & 2.90 & 1.64 \\
\hline Constant difficulty & 2.25 & 0.93 & 6.79 & 1.55 & 2.90 & 1.39 \\
\hline Ascending difficulty & 1.31 & 0.37 & 4.57 & 1.69 & 7.00 & 1.58 \\
\hline Positivity of feedback & 4.50 & 2.20 & 4.57 & 1.99 & 5.00 & 0.71 \\
\hline Neutrality of feedback & 6.63 & 2.20 & 7.43 & 1.90 & 7.40 & 2.61 \\
\hline Negativity of feedback & 3.88 & 2.59 & 4.71 & 1.70 & 3.80 & 1.79 \\
\hline \multicolumn{7}{|l|}{ High self-esteem/perceptions of } \\
\hline Descending difficulty & 7.60 & 1.14 & 3.92 & 1.16 & 3.56 & 2.56 \\
\hline Constant difficulty & 2.30 & 0.76 & 6.50 & 2.32 & 2.38 & 1.77 \\
\hline Ascending difficulty & 2.30 & 1.15 & 3.33 & 0.75 & 6.25 & 2.90 \\
\hline Positivity of feedback & 4.75 & 1.89 & 5.20 & 1.48 & 5.25 & 0.46 \\
\hline Neutrality of feedback & 7.75 & 0.96 & 7.00 & 1.73 & 8.50 & 1.41 \\
\hline Negativity of feedback & 1.25 & 0.50 & 4.00 & 1.41 & 4.88 & 1.25 \\
\hline
\end{tabular}

NOTE: Scores can range from 1 to 9.

experimenter-generated feedback, suggesting that this feedback was appropriate for use in the subsequent studies.

\section{STUDY 1: DOES THE MESSENGER MATTER?}

Our analysis suggests that people with low self-esteem will incorporate positive feedback into their self-assessments of performance on a novel, competence-relevant task when the feedback comes from a credible outside source but not when it comes from the self. In contrast, we expect people with high self-esteem to accept positive feedback about their abilities whether it comes from a credible outside source or the self. To test these ideas, we asked people low and high in self-esteem to solve a series of anagrams that was rigged to provide either positive or neutral self-generated feedback. An experimenter then offered participants either positive or neutral feedback about their performance. We predicted that among persons with low self-esteem, reports of improvement would be more affected by positive experimenter-generated feedback than by positive self-generated feedback. Among people with high self-esteem, we expected reports of improvement to be affected by both the selfgenerated and experimenter-generated feedback.

\section{Method}

\section{PARTICIPANTS}

Participants were 153 introductory psychology students who participated in exchange for course credit. At the beginning of the semester, we administered the SLCS during a mass pretesting session; only those students who scored in the bottom and top $25 \%$ of the sam- ple $(M \mathrm{~s}=2.76$ and 4.65 on a 5-point scale $)$ were eligible for participation. Data from 9 participants were excluded from analyses due to failure to complete the anagram series or suspicion regarding the true purpose of the experiment; thus, the final sample consisted of 144 participants (56 men and 88 women).

\section{PROCEDURE}

In individual testing sessions, participants learned that the purpose of the study was to test the relation between anagram-solving ability and performance on the Graduate Record Exam (GRE). The experimenter emphasized that people who perform well on anagrams also tend to perform well on the GRE, which is "considered an important indicator of overall intellectual functioning." Moreover, because participants' performance on the anagram series was likely to be poor at first due to inexperience with the task, the experimenter noted that improvement across the anagram series, rather than overall performance, was the best indicator of ability.

Participants then began the anagram series, which consisted of 15 five-letter anagrams presented individually on a computer (we used the 12 anagrams from the pilot study plus 3 additional anagrams for which we had normative solution time data). The easiest anagram in the series had a mean solution time of $28 \mathrm{~s}$ and the most difficult anagram had a mean solution time of $83 \mathrm{~s}$. Approximately half of the participants solved anagrams that were ordered from most difficult to easiest (the positive self-generated feedback condition); for the remaining participants, the same 15 anagrams were presented in a random order (the neutral self-generated feedback condition). ${ }^{4}$ Overall solution time across the anagram series was measured for each participant. 
After completing the anagram series, participants received a questionnaire packet that contained several filler questionnaires followed by a single item that served as the dependent measure. Specifically, we asked, "Do you think your performance got better or worse over the series of anagrams?" Participants responded to this item on a scale that ranged from 1 (it got much better) to 9 (it got much worse). This item appeared toward the end of the questionnaire packet so as to allow time for our manipulation of experimenter-generated performance feedback.

Two minutes after participants began working on their questionnaire packets (but before they reached the perceived improvement question), the experimenter interrupted and explained that due to recent trouble with the computer system, it was necessary to save the participant's anagram solution time data now so that it would not be lost. The experimenter then entered some commands into the computer to obtain a screen that ostensibly displayed the participant's anagram statistics. After viewing the screen for approximately $10 \mathrm{~s}$, the experimenter delivered either positive feedback ("Looks good. It seems like you did really well on a couple near the end") or neutral feedback ("This is about what I expected") to the participant. After receiving this feedback, participants finished their questionnaire packets and were debriefed and thanked.

Results

\section{PRELIMINARY ANALYSES}

To ensure that anagram solution times were not confounded with self-esteem level or feedback type, we submitted participants' overall anagram solution times to a 2 (self-esteem: low vs. high) $\times 2$ (self-generated feedback: positive vs. neutral) $\times 2$ (experimenter-generated feedback: positive vs. neutral) between-subjects ANOVA. There were no significant main or interactive effects, all $F_{\mathrm{s}}<1.99, p \mathrm{~s}>.16$. The overall mean solution time across the anagram series was $20.85 \mathrm{~min}$ in the neutral selfgenerated feedback condition and $24.18 \mathrm{~min}$ in the positive self-generated feedback condition.

\section{SELF-RATED IMPROVEMENT}

We expected that both low and high self-esteem participants would report more improvement following positive versus neutral feedback from an experimenter but that only high self-esteem participants would report more improvement following positive versus neutral selfgenerated feedback. That is, we expected people with low self-esteem to appear relatively unaffected by their own feelings of improvement at this novel task. To examine predictions, we first reverse-scored responses to the question, "Do you think your performance got better or
TABLE 2: Means and Standard Deviations for Perceived Improvement (Study 1) and State Self-Esteem (Study 2)

\begin{tabular}{|c|c|c|c|c|}
\hline \multirow[b]{3}{*}{ Self-Esteem/Self-Generated Feedback } & \multirow{2}{*}{\multicolumn{2}{|c|}{$\begin{array}{c}\text { r-Generated Feec } \\
\text { Neutral }\end{array}$}} & \multirow{2}{*}{\multicolumn{2}{|c|}{ Positive }} \\
\hline & & & & \\
\hline & M & SD & M & SD \\
\hline \multicolumn{5}{|l|}{ Low self-esteem } \\
\hline Neutral & 5.27 & 1.53 & 7.41 & 1.06 \\
\hline Positive & 5.40 & 2.20 & 8.04 & 1.04 \\
\hline \multicolumn{5}{|l|}{ High self-esteem } \\
\hline Neutral & 5.14 & 1.56 & 7.43 & 1.50 \\
\hline Positive & 7.04 & 1.22 & 8.67 & 0.62 \\
\hline
\end{tabular}

Study 2: Source of Positive Feedback

\begin{tabular}{llllll} 
& \multicolumn{3}{c}{ Self } & & \multicolumn{2}{c}{ Experimenter } \\
Self-Esteem & $\mathrm{M}$ & $\mathrm{SD}$ & & $\mathrm{M}$ & $\mathrm{SD}$ \\
\hline How & 49.35 & 7.18 & & 54.11 & 6.90 \\
High & 65.38 & 7.35 & & 67.56 & 4.57 \\
\hline
\end{tabular}

NOTE: Perceived improvement scores can range from 1 to 9. State selfesteem scores can range from 16 to 80 .

worse over the series of anagrams?" so that higher scores reflected more improvement. We then submitted perceptions of improvement to a 2 (self-esteem: low vs. high $\times 2$ (self-generated feedback: positive vs. neutral) $\times$ 2 (experimenter-generated feedback: positive vs. neutral) between-subjects ANOVA and used the mean square error term from the omnibus ANOVA in planned contrasts to test our specific predictions.

The resulting pattern of means appears in Table 2. Although the three-way interaction did not reach significance, $F(1,136)=1.37, p=.24$, eta $^{2}=.010$, our predictions were supported by a significant Self-Esteem $\times$ SelfGenerated Feedback interaction, $F(1,136)=6.77, p<$ .05 eta $^{2}=.047 .{ }^{5}$ Planned contrasts confirmed that both low and high self-esteem participants reported more improvement if they received positive, as compared to neutral, feedback from the experimenter, $F \mathrm{~s}>36.00$, $p \mathrm{~s}<$ .001 eta $^{2}>.208$. (This pattern also was demonstrated by a significant main effect of experimenter-generated feedback, $F[1,136]=85.76, p<.001$.) Moreover, whereas low self-esteem participants reported similar improvement following positive and neutral self-generated feedback, $F(1,136)=1.16, p=.28$, eta ${ }^{2}=.008$, those with high self-esteem reported more improvement following positive than neutral self-generated feedback, $F(1,136)=$ $23.29, p<.001$ eta $^{2}=.146$. In addition, people low relative to high in self-esteem, and those who received neutral relative to positive self-generated feedback, reported significantly less improvement on the anagrams, $F \mathrm{~s}>$ $5.63, p s<.05$, eta $^{2}>.039$. Finally, neither the Self-Esteem $\times$ Experimenter-Generated Feedback interaction nor 
the Self-Generated $\times$ Experimenter-Generated Feedback interaction was significant, $F \mathrm{~s}<1$.

\section{Discussion}

The results of Study 1 provide initial evidence of the asymmetric effect of feedback source on self-reported improvement. Following an anagram task, people with low and high self-esteem who received positive feedback from an experimenter reported improvement in their performance, relative to those who received neutral experimenter-generated feedback. On the other hand, following positive self-generated feedback, only people with high self-esteem reported improvement; those with low self-esteem did not claim to have improved on the anagrams despite the fact that they presumably noticed decreases in their solution time per anagram across the series. These findings thus support the idea that people with low self-esteem are unlikely to accept positive feedback about their abilities on a novel task when it comes from the self. A fuller examination of the asymmetric effects of feedback, however, required that we investigate the manner in which people's self-views-and not merely their performance assessments-were altered by the receipt of self- versus experimenter-generated positive feedback.

\section{STUDY 2: STATE SELF-ESTEEM EFFECTS}

In Study 2, we examined whether low and high selfesteem people's feelings of state self-esteem were differentially affected by the experience of receiving positive self-versus experimenter-generated feedback. Our theorizing suggested that people with low-trait self-esteem should have higher state self-esteem following positive experimenter-generated feedback than following positive self-generated feedback. In contrast, those with hightrait self-esteem should experience similar levels of state self-esteem following positive feedback regardless of its source. To explore these predictions, we presented half of our low and high self-esteem participants with a series of anagrams that became progressively easier and then offered them neutral feedback about their performance (positive self-generated feedback condition). We presented the remaining participants with a series of anagrams that were randomly ordered and then offered them praise about their performance on the anagrams (positive experimenter-generated feedback condition). Subsequently, participants rated their state self-esteem and rated their performance on the anagrams.

Method

\section{PARTICIPANTS}

One-hundred introductory psychology students participated in partial fulfillment of a course requirement.
Only students who scored in the bottom or top $25 \%$ of the distribution on the SLCS $(M s=2.30$ and 3.72 on a $4-$ point scale) were eligible for the study. Data from 9 participants were discarded due to suspicion regarding the true purpose of the experiment. The final sample consisted of 33 men and 58 women.

\section{PROCEDURE}

The procedure for Study 2 was similar to that for Study 1, with two exceptions. First, we eliminated the conditions in which participants received two doses of congruent (both positive or both neutral) feedback. Thus, participants who experienced positive self-generated feedback received a neutral comment from the experimenter and those who experienced neutral selfgenerated feedback received praise from the experimenter. The result was a 2 (self-esteem: low vs. high) $\times 2$ (source of positive feedback: self vs. experimenter) design.

Second, after receiving the experimenter's feedback (but before rating their own improvement), participants responded to 16 questions from Heatherton and Polivy's (1991) State Self-Esteem Scale (SSE). The SSE is a 20item scale that measures people's current feelings about themselves in social, performance, and appearance domains (we excluded the four appearance items because they were not relevant to our hypotheses). All items were rated on scales of 1 (not at all) to 5 (extremely), and respondents were instructed to answer with regard to "how [you] are feeling at this moment."

Results

\section{PRELIMINARY ANALYSES}

Replicating the results of Study 1, a 2 (trait selfesteem: low vs. high) $\times 2$ (source of positive feedback: self vs. experimenter) between-subjects ANOVA on overall anagram solution times yielded no significant main or interactive effects, all $F_{\mathrm{s}}(1,87)<1.80, p \mathrm{~s}>.18$. In addition, in Study 2, we recorded participants' solution times for each anagram separately. Results of a 2-between (trait self-esteem: low vs. high) $\times 2$-between (source of positive feedback: self vs. experimenter) $\times 2$-within (anagram block: first three vs. last three) ANOVA revealed a significant Source-of-Feedback $\times$ Anagram-Block interaction, $F(1,87)=53.28, p<.01$. In the positive self-generated feedback condition, mean solution time decreased from $33.37 \mathrm{~s}$ in the first block to $12.37 \mathrm{~s}$ in the last block, $F(1,46)$ $=56.89, p<.01$. In the positive experimenter-generated feedback condition, mean solution time increased from $21.80 \mathrm{~s}$ in the first block to $31.86 \mathrm{~s}$ in the last block, $F(1$, $43)=9.70, p<.05$. Although this increase was statistically significant, we do not view it as psychologically meaningful, in part because it translates into a time-to-solution in- 
crease of less than $1 \mathrm{~s}$ per anagram. Finally, self-esteem did not interact with source of positive feedback, $F(1,87)<1$.

\section{PERCEIVED IMPROVEMENT}

We next examined whether our previous finding regarding self-assessments of improvement would replicate. Results of a two-way ANOVA revealed a significant Trait Self-Esteem $\times$ Feedback Source interaction on participants' self-perceptions of improvement, $F(1,87)=$ $4.76, p<.05$, $^{2} \mathrm{et}^{2}=.052$, and planned contrasts confirmed our previous findings: People with low selfesteem reported more improvement across the anagram series when an experimenter gave them positive feedback than when it came from the self, $M \mathrm{~s}=6.77$ and 5.72, $F(1,87)=6.50, p<.05, \mathrm{eta}^{2}=.070$. In contrast, people with high self-esteem reported equal improvement on the anagrams regardless of whether source of positive feedback was the self or an experimenter, $M \mathrm{~s}=6.96$ and $6.87, F(1,87)<1$. Finally, people low in self-esteem reported less improvement than those high in selfesteem, $F(1,87)=6.62, p<.05$, eta ${ }^{2}=.071$, and people who received positive self-generated feedback reported marginally less improvement than those who received positive feedback from the experimenter, $F(1,87)=3.30$, $p=.073, \mathrm{eta}^{2}=.037$.

\section{STATE SELF-ESTEEM}

Did people's perceptions of improvement across the anagram series translate into changes in state self-esteem? The Trait Self-Esteem $\times$ Feedback Source interaction did not reach significance, $F(1,85)<1$, but planned contrasts confirmed our predictions. ${ }^{6}$ People with low-trait self-esteem who received positive experimenter-generated feedback reported higher state self-esteem than their counterparts who received positive self-generated feedback, $F(1,85)=4.61, p<.05$, eta ${ }^{2}=.051$; in contrast, people with high-trait self-esteem reported similar levels of state self-esteem in both feedback conditions, $F(1,85)=$ $1.49, p=.23, \mathrm{eta}^{2}=.017$ (see Table 2 ). Finally, there was a main effect of trait self-esteem such that people low, relative to those high, in trait self-esteem scored lower in state self-esteem, $F(1,85)=107.23, p<.01$, eta ${ }^{2}=.558$, and people who received positive self-generated feedback reported lower state self-esteem than those who received positive experimenter-generated feedback, $F(1,85)=5.94, p<.05$, eta $^{2}=.065$.

\section{Discussion}

Among people with high self-esteem, the source of positive feedback did not moderate the feedback's influence on perceived improvement across an anagram series or feelings of state self-esteem. However, among people with low self-esteem, perceived improvement on the anagrams and state self-esteem were both higher fol- lowing praise from an experimenter than following the subjective experience of self-generated positive feedback.

Taken together, the results of the pilot study and the first two studies suggest that although people low and high in self-esteem are equally likely to notice changes in the speed with which they can solve anagrams, those low in self-esteem are relatively unlikely to (a) interpret these changes as reflecting improvement in their performance and (b) rely on these changes to boost their temporary feelings of self-worth. This supports our thesis that low self-esteem is resistant to change, in part, because of the reluctance of low self-esteem persons to accept positive, self-enhancing feedback from themselves. To more fully explain the stubborn persistence of low self-esteem, however, it is important to explore whether low self-esteem people also resist self-generated negative feedback.

\section{STUDY 3: SELF AS A SOURCE OF NEGATIVE FEEDBACK}

According to Swann and his colleagues (e.g., Swann, 1990; Swann, Stein-Seroussi, \& McNulty, 1992), people low in self-esteem seek out and accept information and feedback that verifies their negative self-views, even though such behavior can have harmful consequences for their affective states (Swann, Griffin, Predmore, \& Gaines, 1987). If those low in self-esteem categorically reject positive self-generated feedback while embracing negative self-generated feedback, we posit that the puzzle of low self-esteem can be moved one step closer to solution.

To test this idea, we gave participants low in selfesteem the opportunity to experience either negative or neutral self-generated performance feedback and then offered them either negative or neutral experimentergenerated feedback and asked them to rate their improvement across an anagram series. We expected that people with low self-esteem would be willing to incorporate negative self-generated feedback into their self-assessments of performance because, although not necessarily consistent with participants' specific selfviews (indeed, participants presumably did not have preestablished self-views regarding their anagram-solving abilities), negative self-generated feedback, that is, a feeling of failure at a novel task, would be consistent with the low self-esteem person's chronic tendency toward negative self-evaluation (e.g., Britt, Doherty, \& Schlenker, 1997; Brown, Dutton, \& Cook, 2001). Thus, we expected that people with low self-esteem would report less improvement across the anagram series when they received negative versus neutral feedback, regardless of whether the negative feedback came from the self or from an experimenter. 
Method

\section{PARTICIPANTS}

Eighty-seven introductory psychology students participated in partial fulfillment of a course requirement. Only students who scored in the bottom $25 \%$ of the distribution on the SLCS ( $M=2.23$ on a 4-point scale) were eligible for participation. Data from six participants were discarded due to suspicion or inability to complete the tasks within the allotted time; this left a total of 29 men and 52 women.

\section{PROCEDURE}

The procedure for Study 3 was identical to that for Study 1, with a few exceptions. As in Study 1, participants solved a series of anagrams, received experimentergenerated feedback about their performance, and rated their improvement across the anagram series. In contrast with the procedure used in Study 1, participants in Study 3 experienced either neutral or negative feedback. For self-generated feedback, we presented some participants with the same randomly ordered anagram series that was used in the previous two studies, whereas other participants received an anagram series that grew progressively more difficult (we reversed the order of presentation of the progressively easier series that we used in earlier studies). Participants in this condition thus experienced a decline in performance across time, or negative self-generated feedback. For experimentergenerated feedback, some participants received the same neutral feedback from the experimenter as in previous studies; the remaining participants received a negative experimenter comment ("Looks like you had some trouble with a couple of anagrams near the end"). Thus, we employed a 2 (self-generated feedback: negative vs. neutral) $\times 2$ (experimenter-generated feedback: negative vs. neutral) design.

Results

\section{PRELIMINARY ANALYSES}

We performed a two-way ANOVA with self- and experimenter-generated feedback as the independent variables and total anagram solution times as the dependent variable. Replicating our results from earlier studies, this analysis confirmed that there were no main or interactive effects of the independent variables on the speed with which participants were able to complete the anagram series, all $F_{\mathrm{s}}(1,77)<1$.

\section{PERCEIVED CHANGE IN PERFORMANCE}

We expected that low self-esteem people would be affected by both self- and experimenter-generated negative feedback; thus, a decline in performance over time and a negative comment from the experimenter were both expected to result in perceptions of declining per-
TABLE 3: Means and Standard Deviations for Perceived Improvement (Study 3) and Willingness to Accept Feedback (Study 4)

\begin{tabular}{|c|c|c|c|c|}
\hline \multicolumn{5}{|c|}{ Study 3: Experimenter-Generated Feedback } \\
\hline \multirow[b]{2}{*}{ Self-Generated Feedback } & \multicolumn{2}{|c|}{ Neutral } & \multicolumn{2}{|c|}{ Negative } \\
\hline & M & $\mathrm{SD}$ & M & $\mathrm{SD}$ \\
\hline Neutral & 5.81 & 1.66 & 4.32 & 1.60 \\
\hline \multirow[t]{3}{*}{ Negative } & 3.45 & 1.39 & 1.81 & 0.98 \\
\hline & \multicolumn{4}{|c|}{ Study 4: Source of Positive Feedback } \\
\hline & \multicolumn{2}{|c|}{ Self } & \multicolumn{2}{|c|}{ External } \\
\hline Self-Esteem & M & $\mathrm{SD}$ & M & $\mathrm{SD}$ \\
\hline Low & 3.81 & 1.17 & 5.01 & 1.03 \\
\hline High & 5.33 & 0.86 & 5.51 & 0.65 \\
\hline
\end{tabular}

NOTE: Perceived improvement scores can range from 1 to 9 . Willingness to accept feedback scores can range from 1 to 7 .

formance on the anagram series. To test our hypothesis, we performed a 2 (self-generated feedback: negative vs. neutral) $\times 2$ (experimenter-generated feedback: negative vs. neutral) between-subjects ANOVA on ratings of perceived improvement (means and standard deviations for improvement ratings appear in Table 3). As expected, the interaction of self- and experimenter-generated feedback was not statistically significant, $F(1,77)<1$, but both of the main effects were. Specifically, low selfesteem participants who experienced negative self-generated feedback reported less improvement than those who experienced neutral self-generated feedback, $F(1$, $77)=58.45, p<.01$ eta $^{2}=.432$, and participants who received negative feedback from the experimenter reported less improvement than those who received neutral experimenter-generated feedback, $F(1,77)=$ $24.27, p<.01, \mathrm{eta}^{2}=.240$.

\section{Discussion}

People with low self-esteem who experienced either self- or experimenter-generated negative feedback reported less improvement across an anagram series than those who experienced neutral feedback. Why did participants in this study accept negative feedback from themselves when they appeared reluctant to accept positive self-generated feedback in previous studies? Perhaps, consistent with Baumeister et al.'s (1989) model, it is relatively safe for low self-esteem persons to accept negative feedback from themselves because doing so does not put them at risk of appearing boastful. Alternatively, low self-esteem persons may be particularly attentive to negative feedback because it implies potential exclusion (Leary et al., 1995) or they may consider the self a credible source of negative feedback because they are used to receiving such feedback from themselves. 
Regardless of which explanation is correct, this finding provides an additional route through which low selfesteem is maintained.

\section{STUDY 4: SELF-REPORTED ACCEPTANCE}

OF POSITIVE FEEDBACK

Taken together, the results from Studies 1 through 3 suggest that there are self-esteem differences in people's acceptance of self- versus externally generated positive feedback. However, none of the studies presented heretofore offers direct evidence that people low in selfesteem are hesitant to accept positive feedback from themselves. Therefore, in Study 4, we used a self-report methodology to assess participants' willingness to accept positive feedback from the self versus from an outsider. Study 4 also was designed to deal with two additional shortcoming of Studies 1 through 3. First, in the previous studies, we confounded the explicitness of feedback with the source of feedback; that is, the method by which external feedback was given involved an explicit mention of performance, whereas internal feedback was merely implied by anagram performance. We addressed this confound in Study 4 by asking participants about their responses to explicit positive feedback only. Second, in all previous studies, the feedback we administered pertained only to people's abilities in a competencerelevant domain; therefore, in Study 4, we queried participants about their acceptance of feedback in both social and competence domains.

To do this, we presented participants with hypothetical scenarios in which they received positive self- or externally generated feedback about their attractiveness and likability, and we asked them to indicate the likelihood that they would believe this feedback. We also asked participants to indicate the extent to which they generally trusted the self versus other people when determining how good they were at a novel task. We predicted that participants low in self-esteem would rate selfgenerated positive feedback as less believable than externally generated positive feedback but that this difference would not emerge among participants high in selfesteem.

Finally, we also used this self-report methodology to explore questions pertaining to the ecological validity of our proposed esteem-maintenance process. To this end, we assessed participants' subjective likelihood of experiencing the hypothetical scenarios and feedback that we presented. We predicted that relative to participants high in self-esteem, those low in self-esteem would estimate a greater likelihood of receiving negative feedback and a lower likelihood of receiving positive feedback. These predictions derive from research suggesting that people who rely primarily on positive feedback from others to boost their self-esteem, such as those who are shy
(Asendorpf, 1987), depressed (Giesler, Josephs, \& Swann, 1996), or low in self-esteem (Josephs, Larrick, Steele, \& Nisbett, 1992), may structure their social environments in such a way so as to avoid externally generated feedback because they fear it will be negative.

Method

\section{PARTICIPANTS}

Seventy-four introductory psychology students (25 men and 49 women) participated in exchange for credit toward a course requirement. To be eligible, students had to score in the bottom or top $25 \%$ of the distribution ( $M s=2.91$ and 4.79 on a 5-point scale) on the Rosenberg (1965) Self-Esteem Scale (RSES), which was administered during a pretesting session at the beginning of the semester. $^{7}$

\section{PROCEDURE}

An experimenter introduced participants to "an investigation of the learning processes that occur in different situations" and asked them to complete a survey consisting of several parts. First, written instructions asked participants to imagine two hypothetical scenarios in which they received positive feedback of an interpersonal nature. Each scenario appeared twice, with different endings: In one ending, the participant received positive feedback from himself or herself, and in the second ending the participant received similar feedback from an external source. For example, the first scenario read as follows: "You work up the courage to approach someone you have a crush on, but he/she rejects your request for a date." This scenario was followed once by a selfgenerated feedback ending ("To make yourself feel better, you look at your reflection in a mirror and tell yourself 'It's okay, I know I'm attractive anyway' ") and once by an externally generated feedback ending ("On your way home, however, an attractive stranger flirts with you and tells you that you're "very good-looking' "). The second scenario described a situation in which the participant worked in a group with some classmates who treated her badly; in the self-generated feedback ending, the participant told herself that she was not at fault for her groupmates' behavior, and in the externally generated feedback ending the participant's friends told her that she was not at fault. Following each scenario ending, participants rated the extent to which they would believe the feedback on scales ranging from 1 (not at all) to 7 (very much). Next, on these same 7-point scales, participants indicated the extent to which they generally trusted "their own feelings" and "feedback from another person" when deciding how competent they were at a novel task. Approximately half of the participants responded to all of the questions about externally generated feedback before responding to the questions about 
self-generated feedback; the remaining participants answered all of the self-generated feedback questions first. Because order did not qualify any of our findings, we do not discuss this variable further.

The remainder of the questions tapped into the likelihood that participants would find themselves in situations such as those described in the scenarios and receive feedback similar to that described in the scenarios. For example, the questions that pertained to the first scenario were as follows: "How likely is it that someone you were attracted to would reject your request for a date?" "How likely is it that you would reassure yourself that you were attractive after being rejected?" and "How likely is it that a stranger would tell you that you're very goodlooking?" Participants answered all questions on scales ranging from 1 (not at all likely) to 7 (very likely). After completing their surveys, participants were debriefed and thanked.

\section{Results}

We created composite self and external feedback acceptance scores by averaging across responses to the questions about self-generated and externally generated feedback, $\alpha \mathrm{s}=.70$ and .54 , respectively. We then submitted these feedback acceptance scores to a 2-between (self-esteem: low vs. high) $\times$ 2-within (feedback source: self vs. external) ANOVA (means and standard deviations appear in Table 3). A significant main effect of feedback source emerged, showing that participants claimed to accept externally generated positive feedback more readily than self-generated positive feedback, $F(1,72)=27.04, p<.001, \mathrm{eta}^{2}=.273$. Moreover, a main effect of self-esteem showed that people with low selfesteem were less trusting of positive feedback than were people with high self-esteem, $F(1,72)=26.95, p<.001$, $\mathrm{eta}^{2}=.272$. These main effects were qualified by a SelfEsteem $\times$ Feedback-Source interaction, $F(1,72)=15.16$, $p<.001$ eta $^{2}=.174$. Planned contrasts confirmed that people with low self-esteem believed externally generated positive feedback more readily than they believed positive feedback from themselves, $F(1,72)=52.76, p<$ .001 , eta $^{2}=.423$, but people with high self-esteem believed both externally and self-generated positive feedback equally, $F<1$.

We next conducted a series of one-way ANOVAs in which we compared low and high self-esteem participants' reports of the likelihood that they would encounter the situations and feedback described in the scenarios. As expected, people with low self-esteem perceived a greater likelihood of being rejected by someone to whom they were attracted than did people with high selfesteem, $M s=4.00$ and 3.28, respectively, $F(1,72)=5.47, p$ $<.05$, eta $^{2}=.071$. Despite their relatively high perceived likelihood of rejection, however, people low (as com- pared to high) in self-esteem indicated that they were unlikely to reassure themselves they were attractive, $M \mathrm{~s}=$ 2.51 and $4.14, F(1,72)=17.08, p<.01$ eta $^{2}=.192$. Moreover, people with low self-esteem believed that positive feedback from a stranger was less likely for them than did people with high self-esteem, $M \mathrm{~s}=3.29$ and $4.41, F(1,72)$ $=8.82, p<.01$, eta $^{2}=.109$.

With regard to the second scenario, people low-relative to those high-in self-esteem believed it more likely that a group of their classmates would mistreat them, $M \mathrm{~s}$ $=2.64$ and 2.14, $F(1,72)=3.89, p=.052$ eta $^{2}=.051$. In this case, whereas people with low self-esteem were less likely than their high self-esteem counterparts to reassure themselves that they were not at fault, $M \mathrm{~s}=4.24$ and $5.48, F(1,72)=9.12, p<.01$, eta $^{2}=.112$, both self-esteem groups thought it equally likely that their friends would tell them they were not at fault for their groupmates' behavior, $M \mathrm{~s}=6.07$ and $6.41, F(1,72)=1.56, p=.22$ eta $^{2}=$ .021 .

\section{Discussion}

The results of Study 4 provide direct evidence that people low in self-esteem are reluctant to accept positive feedback from themselves in both social and competence domains. Whereas high self-esteem participants reported being equally trusting of self-generated and externally generated positive feedback, those with low self-esteem rated self-generated positive feedback as less believable than feedback that came from an external source. Moreover, relative to those high in self-esteem, people low in self-esteem predicted a higher likelihood of experiencing rejection and a lower likelihood of receiving positive feedback, regardless of its source (an exception to this pattern was found for the group activity scenario).

These results therefore suggest several important factors that may underlie self-esteem maintenance. Whereas those high in self-esteem indicate a strong belief in the legitimacy of positive feedback in the aftermath of rejection, those low in self-esteem may maintain their level of self-esteem by (a) finding themselves in esteem-threatening situations more often than their high-esteem counterparts, (b) failing to offer themselves positive feedback after experiencing threats to their selfesteem, and (c) discounting the self-generated positive feedback that they do offer themselves. It is arguable, of course, that participants' self-reports of the likelihood of experiencing esteem-threatening situations derive more from their theories about themselves than from their actual experiences; these data therefore do not speak to self-esteem differences in the frequency with which people actually experience rejection or offer themselves positive feedback. Still, these self-reports are important because they provide fairly straightforward evidence that 
low self-esteem persons at least perceive rejection in their environments, even if this rejection is not real (e.g., Leary et al., 1995).

A final point merits attention here. Note that two of the scenarios we used in Study 4 assessed people's willingness to accept positive feedback in a domain in which they had just experienced interpersonal rejection. In these (and other) situations, it may actually be more rational and adaptive to believe positive feedback from an outsider than from the self. That is, if one has received the clear message that one's company is not welcome, a friend's or stranger's unsolicited reassurance might be a more reliable measure of reality than one's own positive self-talk. We therefore do not suggest that it is always irrational to reject self-generated positive feedback or that it is always adaptive and healthy to accept positive feedback regardless of its source. Indeed, it is entirely possible that people with low self-esteem are wise to exercise caution when it comes to believing their own feelings of success and that people with high self-esteem are exhibiting "positive illusions" when they indiscriminately accept flattering feedback and evaluations (Taylor \& Brown, 1988). Thus, our model concerns self-esteem differences in people's chronic tendencies to accept versus reject self-generated positive feedback and how these might serve to maintain their self-esteem-not selfesteem differences in people's ability to distinguish accurate from inaccurate feedback.

\section{GENERAL DISCUSSION}

The findings reported here point to the critical role that the source of feedback plays in determining its impact on persons with low self-esteem. In Studies 1, 2, and 4, we demonstrated that low and high self-esteem people respond differently to positive feedback depending on whether such feedback comes from an internal or external source. Specifically, high self-esteem people appeared to accept positive feedback indiscriminately, placing as much stock in subjective, self-generated feelings of task mastery and self-directed reassurances as they did in praise from an experimenter or other outsider. In contrast, those with low self-esteem accepted positive feedback and reassurance more readily when it came from an external source than when it came from the self. Of importance, people's willingness to accept feedback may determine the impact of the feedback on their self-esteem: As shown in Study 2, low self-esteem people were not only reluctant to incorporate positive self-generated feedback into their assessments of performance at a novel task, but they were also reluctant to incorporate such feedback into their assessments of selfworth. That is, people with low self-esteem displayed lower state self-esteem following positive self-generated feedback than following positive experimenter-generated feedback.

The results of Study 3 suggest that, unfortunately, low self-esteem people do not have as much difficulty accepting negative self-generated feedback as they have accepting positive self-generated feedback (see also Swann, 1990). We propose that this troubling asymmetry may shed light on the stubborn nature of low self-regard. When people with low self-esteem are confronted with a situation in which externally generated feedback is missing or neutral but self-generated feedback is positive, they are reluctant to accept the self-generated feedback. On the other hand, when external feedback is missing or ambiguous but self-generated feedback is negative, persons with low self-esteem are affected by it. Apparently, self-generated feedback does not improve the self-views of people with low self-esteem but it may serve to maintain or perhaps even depress their negative self-views. As discussed below, this finding both confirms and adds to previous findings regarding self-esteem maintenance.

\section{Self-Esteem Maintenance}

As noted earlier, self-esteem tends to remain stable across time (Baumeister, 1993). Although a comprehensive model of low self-esteem maintenance has yet to be offered, theorists have discussed some of the processes responsible for the stubborn persistence of negative selfregard. For example, Festinger (1954) proposed that people with low self-esteem put more emphasis on social comparison information than do people with high selfesteem, suggesting that the former may be at the mercy of external appraisals and perhaps rely excessively on external sources of information to draw conclusions about the self (see also Leary \& Downs, 1995). The pattern of findings presented in this article, although not providing a direct test of these ideas, is at least consistent with Festinger's theorizing: Our high self-esteem participants accepted feedback from the self as well as from an external source, whereas our low self-esteem participants based their self-assessments primarily on externally generated feedback (except when self-generated feedback was negative).

At first glance, a possible alternate route to high selfesteem seems obvious: If low self-esteem people could elicit frequent, positive feedback from the environment, this might compensate for their reluctance to capitalize on positive self-generated feedback. In the short run, externally generated positive feedback may temporarily boost the self-esteem of people who doubt their own credibility; ultimately, such feedback might even result in permanent self-esteem increases. Unfortunately, however, the solution may not be that simple. As Swann's (1990) work on self-verification suggests, people with low self-esteem often prefer to receive negative over posi- 
tive feedback from others. In fact, low self-esteem people may actively work to ensure that their social environments provide them with feedback that confirms their negative self-views. Moreover, even when low self-esteem persons receive positive, verbal feedback from realworld external sources, this feedback is often paired with negative, nonverbal feedback that renders it ambiguous (Swann et al., 1992). Thus, the feedback that may be most effective in helping people with low self-esteem to overcome their feelings of inferiority-positive, externally generated feedback-may be relatively rare. Our finding that low self-esteem people believed it relatively unlikely that they would receive positive feedback from an outside source supports this "rarity of feedback" hypothesis.

\section{Directions for Further Study}

The mental health field embraces a number of different professions, methodologies, and theoretical orientations. Despite the breadth of the field, some broad distinctions are possible. For example, most therapies can be categorized based on the source of feedback on which they rely. Groups such as Alcoholics Anonymous and Weight Watchers incorporate considerable amounts of externally generated feedback into their programs; the members of these groups are partially responsible for providing support and praise for one another. Other sources of help, which include self-help books such as Harris's (1969) well-known I'm OK, You're OK, instead concentrate on the development and use of self-generated feedback. Specifically, these self-help sources assume that "self-affirmations"-positive self-statements that can be considered analogous to self-generated feedbackare an effective technique for raising self-esteem.

Whereas support groups and other types of therapies that include elements of externally generated feedback may be extremely helpful for those with varying levels of self-esteem, our findings suggest that interventions that rely exclusively on self-generated feedback may be less likely to succeed among those with low self-esteem. At least in some contexts, people with low self-esteem appear unable to accept positive feedback that stems from the self. Granted, we looked at people's temporary feelings of state self-esteem here and did not examine the possible long-term consequences of positive, selfgenerated feedback. Nonetheless, we propose that for permanent increases in self-esteem to occur, minor, incremental changes must take root, and our data suggest that such changes may not take root in self-concepts fraught with insecurity and doubt. Thus, some popular self-help techniques may be based on the faulty assumption that those who need help are capable of generating and accepting the cognitions required to help them- selves. Although a considerable gap exists between our current research and these speculations, we believe that the application of our findings to the field of self-help research is theoretically promising, and we hope to demonstrate this empirically in the future.

A second direction for future research involves pinpointing the precise reason why people with low selfesteem have difficulty accepting their own self-directed positive feedback. In this article, we entertained three different possibilities-impression management concerns, chronic overattentiveness to rejection cues, and difficulty perceiving the self as credible-but our data do not allow us to draw conclusions regarding which, if any, of these perspectives provides the best explanation for our findings. Moreover, note that these perspectives, and the explanations they offer, are not mutually exclusive; it is certainly possible that some combination of these (and/or additional) self-esteem-related processes work in tandem to ensure that low self-esteem people will hesitate to embrace their own feelings of success. Thus, although a thorough explanation for the underlying mechanism is beyond the scope of this article, we believe that the pursuit of this question will yield greater insight into the "puzzle of low self-regard."

Finally, because we relied on a nonclinical sample to test our hypotheses, it is possible that the self-esteem of our "low self-esteem" participants was only moderatelyrather than truly-low. After all, most undergraduates report having high self-esteem (e.g., Taylor \& Brown, 1988), and even people who appear to have low selfesteem in a relative sense, that is, people who score in the bottom 25th percentile on a self-esteem scale, do not necessarily have low self-esteem in an absolute sense (Baumeister et al., 1989). It would therefore be illuminating to replicate these findings in a sample of people who strongly dislike themselves, such as individuals who are undergoing treatment for clinical depression. We suspect that our effects would be even stronger among people who possess predominantly negative self-views, but this hunch awaits empirical investigation.

\section{SUMMARY AND CONCLUSIONS}

In the years since Festinger's (1954) theorizing, many researchers have empirically documented differences in the ways people with high and low self-esteem react to similar feedback. Although the methodologies and results of these studies are diverse, there is a general tendency for people with low self-esteem to be more strongly affected by feedback than are those with high self-esteem (e.g., Brockner, 1988; Shrauger \& Sorman, 1977). Consistent with several theories of low selfesteem, our findings demonstrate an important exception to this general tendency, an exception that poten- 
tially provides insight into the puzzle of low self-regard: People with low self-esteem are apparently resistant to feedback when the feedback is positive and the source is the self. Unfortunately, the low self-esteem person's reluctance to accept positive self-generated feedback, combined with the rarity of externally generated positive feedback (e.g., Josephs et al., 1992; Swann et al., 1992), may result in a downward spiral from which recovery is difficult.

\section{NOTES}

1. To confirm that there were no meaningful self-esteem differences in perceived change across the anagrams, we estimated the number of participants we would need per condition to obtain significant self-esteem interaction effects. Given that eta ${ }^{2}<.03$ for each interaction involving self-esteem (and setting power at .60), we would have needed an $N$ of more than 250 people per condition to find significant interactions of self-esteem with any other variable (see Rosenthal \& Rosnow, 1991).

2. Degrees of freedom for this analysis differ from those in the previous ANOVA because two participants failed to rate the experimenter's feedback.

3 . We estimated the number of participants we would need per condition to obtain significant self-esteem interaction effects. For the SelfEsteem $\times$ Perceptions-of-Feedback interaction, eta $^{2}=.059$; for the three-way interaction, eta $^{2}=.063$. Thus, setting power at .60 , we would have needed an $N$ of approximately 200 people per condition to find significant interactions with self-esteem (see Rosenthal \& Rosnow, 1991). Even relaxing power to a level (.40) that would result in a greater than $50 \%$ chance of a Type II error, we would need approximately 130 people per condition to achieve statistically significant interactions with self-esteem.

4. We programmed the computer to reveal the first letter of the solution on the screen if $5 \mathrm{~min}$ passed without the participant entering the correct solution. Three participants required this clue and all of them solved the anagram correctly within a minute of receiving it.

5 . We do not consider it problematic that the three-way interaction did not reach significance. An increasing number of researchers are arguing that multiway (three-way and greater) ANOVAs are difficult to interpret correctly and are not appropriate tests of the great majority of hypotheses (e.g., Harlow, Mulaik, \& Steiger, 1997; Rosnow \& Rosenthal, 1995).

6. Degrees of freedom differ for this analysis because two participants did not complete the entire State Self-Esteem Scale.

7. We switched to the Rosenberg here because, due to an oversight, the Self-Liking and Self-Competence Scale (SLCS) was not pretested. The Rosenberg is correlated at approximately .70 with the SLCS.

\section{REFERENCES}

Asendorpf, J. B. (1987). Videotape reconstruction of emotions and cognitions related to shyness. Journal of Personality and Social Psychology, 53, 542-549.

Baumeister, R. (1993). Self-esteem: The puzzle of low self-regard. New York: Plenum.

Baumeister, R. F., Tice, D. M., \& Hutton, D. G. (1989) . Self-presentation motivations and personality differences in self-esteem. Journal of Personality, 57, 547-579.

Baumgardner, A. H., Kaufman, C., \& Levy, P. (1989). Regulating affect interpersonally: When low self-esteem leads to greater enhancement. Journal of Personality and Social Psychology, 56, 907-921.

Blaine, B., \& Crocker, J. (1993). Self-esteem and self-serving biases in reactions to positive and negative events. In R. F. Baumeister
(Ed.), Self-esteem: The puzzle of low self-regard (pp. 55-85). New York: Plenum.

Bowlby, J. (1969). Attachment and loss: Vol. 1. Attachment. New York: Basic Books.

Britt, T. W., Doherty, K., \& Schlenker, B. R. (1997). Self-evaluation as a function of self-esteem, performance feedback, and selfpresentational role. Journal of Social and Clinical Psychology, 16, 463483.

Brockner, J. (1988). Self-esteem at work: Research, theory, and practice. Lexington, MA: D. C. Heath.

Brown, J. D. (1991). Accuracy and bias in self-knowledge. In C. R. Snyder \& D. R. Forsyth (Eds.), Handbook of social and clinical psychology: The health perspective (pp. 158-178). Elmsford, NY: Pergamon.

Brown, J. D., Dutton, K. A., \& Cook, K. E. (2001). From the top down: Self-esteem and self-evaluation. Cognition and Emotion, 15, 615631.

Campbell, J. D. (1990). Self esteem and the clarity of self-concept. Journal of Personality and Social Psychology, 59, 538-549.

Festinger, L. (1954). A theory of social comparison processes. Human Relations, 7, 117-140.

Giesler, R. B., Josephs, R. A., \& Swann, W. B., Jr. (1996). Self-verification in clinical depression: The desire for negative evaluation. Journal of Abnormal Psychology, 105, 358-368.

Harlow, L. L., Mulaik, S. A., \& Steiger, J. H. (1997). What if there were no significance tests. Mahwah, NJ: Lawrence Erlbaum.

Harris, T. A. (1969). I'm OK, you're OK. New York: Avon Books.

Heatherton, T. F., \& Polivy, J. (1991). Development and validation of a scale for measuring state self-esteem. Journal of Personality and Social Psychology, 60, 1991.

Josephs, R. A., Larrick, R. P., Steele, C. M., \& Nisbett, R. E. (1992) . Protecting the self from the negative consequences of risky decisions. Journal of Personality and Social Psychology, 62, 26-37.

Josephs, R. A., Silvera, D. H., \& Giesler, R. B. (1996). The learning curve as a source of metacognitive awareness. Journal of Experimental Psychology: Learning, Memory, and Cognition, 22, 510-524.

Leary, M. R., \& Downs, D. (1995). Interpersonal functions of the selfesteem motive: The self-esteem system as a sociometer. In M. Kernis (Ed.), Efficacy, agency, and self-esteem. New York: Plenum.

Leary, M. R., Tambor, E. S., Terdal, S. K., \& Downs, D. L. (1995). Selfesteem as an interpersonal monitor: The sociometer hypothesis. Journal of Personality and Social Psychology, 68, 518-530.

Petty, R. E., \& Cacioppo, J. T. (1986). Communication and persuasion: Central and peripheral routes to attitude change. New York: SpringerVerlag.

Rosenberg, M. (1965). Society and the adolescent self-image. Princeton, NJ: Princeton University Press.

Rosenthal, R., \& Rosnow, R. L. (1991). Essentials of behavioral research: Methods and data analysis. New York: McGraw-Hill.

Rosnow, R. L., \& Rosenthal, R. (1995). "Some things you learn aren't so": Cohen's paradox, Asch's paradigm, and the interpretation of interaction. Psychological Science, 6, 3-9.

Shrauger, J. S., \& Sorman, P. B. (1977). Self-evaluations, initial success and failure, and improvement as determinants of persistence. Journal of Consulting and Clinical Psychology, 45, 484-495.

Steele, C. M. (1988). The psychology of self-affirmation: Sustaining the integrity of the self. In L. Berkowitz (Ed.), Advances in experimental social psychology (Vol. 21, pp. 261-302). Orlando, FL: Academic Press.

Swann, W. B., Jr. (1990). To be adored or to be known? The interplay of self-enhancement and self-verification. In R. M. Sorrentino \& E. T. Higgins (Eds.), Motivation and cognition (pp. 404-448). New York: Guilford.

Swann, W. B., Griffin, J. J., Predmore, S. C., \& Gaines, B. (1987). The cognitive-affective crossfire: When self-consistency confronts selfenhancement. Journal of Personality and Social Psychology, 52, 881889.

Swann, W. B., Jr., Stein-Seroussi, A., \& McNulty, S. E. (1992). Outcasts in a white-lie society: The enigmatic worlds of people with nega- 
tive self-conceptions. Journal of Personality and Social Psychology, 62, 618-624.

Tafarodi, R. W., \& Swann, W. B., Jr. (1995). Self-liking and selfcompetence as dimensions of global self-esteem: Initial validation of a measure. Journal of Personality Assessment, 65, 322-342.

Taylor, S. E., \& Brown, J. D. (1988). Illusion and well-being: A social psychological perspective on mental health. Psychological Bulletin, 103, 193-210.
Tesser, A. (1988). Toward a self-evaluation maintenance model of social behavior. In L. Berkowitz (Ed.), Advances in experimental social psychology (Vol. 21, pp. 181-227). Orlando, FL: Academic Press.

Received March 12, 2002

Revision accepted August 24, 2002 